\title{
Mechanical Characteristics of SPG-178 Hydrogels: Optimizing Viscoelastic Properties through Microrheology and Response Surface Methodology
}

\author{
Mansooreh-Sadat Seyedkarimi ${ }^{1,2^{*}}$, Hamid Mirzadeh ${ }^{1 *}$, Aliasghar \\ Mohammadi $^{3}$ and Shadab Bagheri-Khoulenjani ${ }^{1}$ \\ ${ }^{1}$ Polymer and Color Engineering Department, Amirkabir University of Technology, Tehran, \\ Iran; ${ }^{2}$ Malek-Ashtar University of Technology, Tehran, Iran; ${ }^{3}$ Department of Chemical \\ and Petroleum Engineering, Sharif University of Technology, Tehran, Iran
}

Received 9 March 2019; accepted 15 April 2019; published online 3 November 2019

\begin{abstract}
Background: SApeptides have growing applications in tissue engineering and regenerative medicine. The application of SApeptide-based hydrogels depends strongly on their viscoelastic properties. Optimizing the properties is of importance in tuning the characteristics of the hydrogels for a variety of applications. Methods: In this study, we employed statistical modeling, conducted with the RSM and particle tracking microrheology, to investigate the effects of self-assembling SPG-178 peptide and added $\mathrm{NaCl}$ salt concentrations and milieu type (DI water or blood serum) on the viscoelastic properties of SPG-178 hydrogels. A central composite RSM model was employed for finding the optimum value of the parameters to achieve the highest storage modulus and the lowest $\tan \delta$. Results: Viscoelastic properties of each sample, including storage modulus, loss modulus, and $\tan \delta$, were determined. Storage modulus and $\tan \delta$ were modeled, accounting for the impact of the SPG-178 peptide and $\mathrm{NaCl}$ concentrations and milieu type on the viscoelastic properties. It was found that the SPG-178 hydrogel storage modulus was positively influenced by the SPG-178 peptide concentration and the serum. Conclusion: A combination of microrheology and RSM is a useful test method for statistical modeling and analysis of rheological behavior of solid-like gels, which could be applied in various biomedical applications such as hemostasis. DOI: 10.29252/ibj.24.2.110
\end{abstract}

Keywords: Hydrogels, Regenerative medicine, Rheology, Tissue engineering, SPG-178

\section{Corresponding Authors:}

Hamid Mirzadeh

Polymer and Color Engineering Department, Amirkabir University of Technology, Tehran, Iran; Tel./Fax.: (+98-21) 66492877;

E-mail: Mirzadeh@aut.ac.ir

Mansooreh-Sadat Seyedkarimi

Polymer and Color Engineering Department, Amirkabir University of Technology, Tehran, Iran; E-mail: seyedkarimi@aut.ac.ir

\section{INTRODUCTION}

$\mathrm{S}$ elf-assembling peptides are very promising biopolymers for biomedical and tissue engineering applications ${ }^{[1-3]}$. SApeptides lead to the formation of peptide nanofibers, which aggregate into hydrogel scaffold networks in physiological conditions $^{[4-6]}$.

There are various SApeptides reported in the literature. EAK16 is one of the first peptides introduced as a SApeptides. EAK16 contains selfcomplementary units that can spontaneously self- 
assemble in proper media ${ }^{[7]}$. RADA16 is the most investigated SApeptides and is well known for its application in hemostasis and tissue regeneration ${ }^{[8-10]}$. SPG-178 is the most recently introduced SApeptides with the amino acid sequence of $\left[\mathrm{CH}_{3} \mathrm{CONH}\right]-$ RLDLRLALRLDLR-[CONH $\left.{ }_{2}\right] \quad(\mathrm{R}, \mathrm{L}, \mathrm{D}$, and A indicate arginine, leucine, aspartic acid, and alanine, respectively), forming a fibrillar hydrogel structure via the self-assembling process, similar to RADA16 ${ }^{[11]}$. SPG-178 hydrogel has potential applications in tissue engineering, including vitreous substitute for eyes ${ }^{[12]}$, bone regeneration $^{[13,14]}$, neurite outgrowth of the spinal motor neurons ${ }^{[15]}$, and rapid hemostasis ${ }^{[16]}$. Due to its neutral $\mathrm{pH}$ value in water as well as its resistance to autoclaving conditions, SPG-178 is easier to handle in comparison to RADA16-I. Besides, the stiffness of SPG-178 hydrogel is slightly higher than that of RADA16 hydrogel in similar conditions ${ }^{[16,17]}$.

In a variety of applications, mechanical properties of SApeptides have to be within a specified range ${ }^{[18]}$. Particularly for hemostasis, it is necessary to form an elastic hydrogel to prevent hemorrhage ${ }^{[19]}$. Therefore, it is of importance to develop a method for tailoring the mechanical properties of the SApeptides. This goal can be achieved via either functionalization and insertion of motifs into the peptide structure ${ }^{[20-22]}$ or adjustment of formulation and self-assembling conditions of the SApeptides, for instance, through controlling the added salt $^{[23-25]}$ or peptide concentrations ${ }^{[26,27]}$.

Precise measurement of the viscoelastic properties of SApeptides is crucial for their optimization in different applications. Traditionally, viscoelastic properties are provided through rheological measurements, undertaken using rheometers. However, the traditional rheometers are limited to low frequencies. Even though low frequency range is appropriate for solid- or liquid-like behavior, there are many complex fluids with microstructural relaxations that occur at higher frequencies. On the other hand, these devices require milliliter-scale material samples, but most biological samples are available in much lower quantities. Since the stress or strain is applied from boundaries, the bulk viscoelastic properties are measured, and the heterogeneities are not probed. This is a serious limitation for non-homogeneous materials with various microstructural length scales. Moreover, the traditional rheometers are not applicable to nonconventional geometries, such as thin films or the interior of biological cells and membranes. Therefore, such limitations have motivated the development of a number of techniques to probe the viscoelastic properties of materials on microscopic length scales. These microrheological techniques can probe local viscoelastic properties from small sample volumes over a wide frequency range ${ }^{[28-31]}$.

There are two general categories for microrheology: active and passive ${ }^{[32]}$. In the active method, embedded micro-sized probe particles are manipulated by external forces. In the passive method, the probe particles are driven solely by thermal forces, and the intrinsic Brownian motion of the particles is monitored. The motion contains information about the local surrounding microenvironment ${ }^{[33]}$. In passive microrheological experiments, the trajectory of the probe particles is measured, and the mechanical properties of the surrounding medium are determined through the well-known generalized Stokes-Einstein relation $^{[34]}$.

In our previous work, microrheological responses of RADA16-I hydrogel were analyzed using the $\mathrm{RSM}^{[35]}$. Employing the RSM minimizes the number of experimental sets required to model and optimize the intended responses, such as viscoelastic properties $^{[36-38]}$. In this study, we examine the impact of experimentally controllable parameters (peptide concentration, added $\mathrm{NaCl}$ salt concentration, and milieu type) on the mechanical properties of SPG-178 hydrogels through passive microrheology and RSM. For this purpose, various experiments were performed according to the sets proposed by Design-Expert Software version 7.0. In addition, the optimum values of the experimentally controllable parameters were determined to achieve the highest stiffness for the SPG-178 hydrogels. To the best of our knowledge, no report has been published in the literature on microrheological studies of the SPG-178 hydrogel and optimization of its viscoelastic properties using RSM.

\section{MATERIALS AND METHODS}

\section{Materials}

SPG-178 peptide, as lyophilized powder, was purchased from ShineGene Molecular Biotech (China). Human blood serum specimens were prepared from a single reference and filtered using a 0.2-micron syringe filter. $\mathrm{NaCl}$ salt was procured from Merck (USA). Polystyrene particles (78452, diameter $2 \pm 0.05 \mu \mathrm{m}$ ) were provided as a $10 \mathrm{wt} \%$ aqueous suspension by the manufacturer (Sigma-Aldrich, USA).

\section{Sample preparation and experimental procedures}

Samples were prepared by mixing the desired proportions of colloidal particles, peptide solutions, salt solutions, and milieu. Aqueous stock solutions of the particles were prepared at the concentration of 150 ppm by diluting with DI water. Aqueous stock solutions of peptide were prepared at the concentrations of $1.5,5,8.5$, and $10 \mathrm{~g} / \mathrm{L}$ by dissolving 
Table 1. Coded levels of experimentally controllable parameters for experiment design

\begin{tabular}{lccccc}
\hline \multirow{2}{*}{ Variables } & \multicolumn{5}{c}{ Ranges and levels } \\
\cline { 2 - 6 } & $\mathbf{- \alpha ( - 1 . 4 )}$ & $\mathbf{- 1}$ & $\mathbf{0}$ & $\mathbf{+ 1}$ & $+\boldsymbol{\alpha}(\mathbf{1 . 4})$ \\
\hline Peptide concentration $(\mathrm{g} / \mathrm{L})$ & 0 & 0.45 & 1.5 & 2.55 & 3 \\
$\mathrm{NaCl}$ concentration $(\mathrm{mM})$ & 0 & 36 & 123 & 210 & 246 \\
Milieu type & \multicolumn{5}{c}{ DI water or serum } \\
\cline { 2 - 6 }
\end{tabular}

appropriate amounts of SPG-178 in DI water, followed by sonication for $30 \mathrm{~min}$. In addition, aqueous stock solutions of $\mathrm{NaCl}$ were prepared at the concentrations of $120,410,700$, and $820 \mathrm{mM}$ by dissolving appropriate amounts of $\mathrm{NaCl}$ in $\mathrm{DI}$ water. Due to the importance of blood-material interaction in clinical applications of SApeptides, half of the tests were carried out in the serum milieu. A leak-proof ovalshaped cavity channel with a diameter of $\sim 1.5 \mathrm{~cm}$ was cut into parafilm and attached on a glass microscope slide. Then $10 \mu \mathrm{L}$ of the desired peptide, salt, and milieu solutions and $3 \mu \mathrm{L}$ of the colloidal suspension were poured into the cavity and mixed by pipetting to prepare the gel compositions. Afterwards, the loaded cavity was covered with a $0.17 \mathrm{~mm}$-thick glass coverslip. It should be noted that a central composite design was employed for experiments in RSM to investigate the effects of the experimentally controllable parameters. The parameters were coded at the levels of $-1.4,-1,0,+1$, and +1.4 with the peptide concentration being set in the range of $0-3 \mathrm{~g} / \mathrm{L}, \mathrm{NaCl}$ concentration in the range of $0-246 \mathrm{mM}$, and the milieu type being either DI water or the serum (Table 1). Twenty-four sets were suggested by Design-Expert Software (version 7.0) for passive microrheology experiments (Table 2).

Passive microrheology experiments were conducted with an inverted optical microscope equipped with a $60 \times / \mathrm{NA} 1.0$ water immersion objective lens (UMPLFLN 60XW, Olympus, Germany) by

Table 2. Measured and predicted $\mathrm{G}^{\prime}$ and $\tan \delta$, with equations $1-4$, for experimental sets

\begin{tabular}{|c|c|c|c|c|c|c|c|}
\hline $\begin{array}{c}\text { Run } \\
\text { number }\end{array}$ & $\begin{array}{c}\text { Peptide } \\
\text { concentration } \\
(\mathrm{g} / \mathrm{L})\end{array}$ & $\begin{array}{c}\mathrm{NaCl} \\
\text { concentration } \\
(\mathbf{m M})\end{array}$ & $\begin{array}{c}\text { Milieu } \\
\text { type }\end{array}$ & $\begin{array}{c}\text { Measured } \\
\mathrm{G}^{\prime}(\mathrm{Pa}) \\
\text { at } 10 \mathrm{rad} \mathrm{s^{-1 }}\end{array}$ & $\begin{array}{c}\text { Measured } \\
\tan \delta \\
\text { at } 10 \mathrm{rad} \mathrm{s} s^{-1}\end{array}$ & $\begin{array}{c}\text { Predicted } \\
\mathrm{G}^{\prime}(\mathrm{Pa}) \\
\text { at } 10 \mathrm{rad} \mathrm{\textrm {s } ^ { - 1 }}\end{array}$ & $\begin{array}{c}\text { Predicted } \\
\tan \delta \\
\text { at } 10 \mathrm{rad} \mathrm{s}^{-1}\end{array}$ \\
\hline 1 & 0.45 & 36.00 & DI water & 0.30 & 4.17 & 0.06 & 5.51 \\
\hline 2 & 2.55 & 36.00 & DI water & 0.35 & 2.50 & 0.73 & 1.73 \\
\hline 3 & 0.45 & 210.00 & DI water & 3.56 & 0.94 & 1.09 & 1.42 \\
\hline 4 & 2.55 & 210.00 & DI water & 2.96 & 0.60 & 4.54 & 0.63 \\
\hline 5 & 0.00 & 123.00 & DI water & 0.005 & 11.6 & 0.23 & 3.78 \\
\hline 6 & 3.00 & 123.00 & DI water & 5.78 & 0.78 & 2.87 & 0.88 \\
\hline 7 & 1.50 & 0.00 & DI water & 0.067 & 2.66 & 0.12 & 3.5 \\
\hline 8 & 1.50 & 246.00 & DI water & 2.18 & 0.92 & 3.13 & 0.72 \\
\hline 9 & 1.50 & 123.00 & DI water & 2.87 & 0.82 & 3.24 & 0.79 \\
\hline 10 & 1.50 & 123.00 & DI water & 3.10 & 0.60 & 3.24 & 0.79 \\
\hline 11 & 1.50 & 123.00 & DI water & 3.36 & 1.00 & 3.24 & 0.79 \\
\hline 12 & 1.50 & 123.00 & DI water & 4.20 & 0.85 & 3.24 & 0.79 \\
\hline 13 & 0.45 & 36.00 & Serum & 3.50 & 0.47 & 1.34 & 0.65 \\
\hline 14 & 2.55 & 36.00 & Serum & 3.55 & 0.86 & 4.95 & 1.06 \\
\hline 15 & 0.45 & 210.00 & Serum & 3.37 & 1.00 & 1.39 & 1.68 \\
\hline 16 & 2.55 & 210.00 & Serum & 7.08 & 0.59 & 6.80 & 0.58 \\
\hline 17 & 0.00 & 123.00 & Serum & 0.012 & 9.86 & 1.13 & 1.27 \\
\hline 18 & 3.00 & 123.00 & Serum & 9.20 & 0.85 & 7.75 & 0.85 \\
\hline 19 & 1.50 & 0.00 & Serum & 2.68 & 1.00 & 2.24 & 0.68 \\
\hline 20 & 1.50 & 246.00 & Serum & 2.08 & 0.79 & 3.35 & 0.72 \\
\hline 21 & 1.50 & 123.00 & Serum & 4.95 & 0.97 & 4.17 & 0.86 \\
\hline 22 & 1.50 & 123.00 & Serum & 2.32 & 0.67 & 4.17 & 0.86 \\
\hline 23 & 1.50 & 123.00 & Serum & 3.74 & 0.93 & 4.17 & 0.86 \\
\hline 24 & 1.50 & 123.00 & Serum & 4.90 & 0.98 & 4.17 & 0.86 \\
\hline
\end{tabular}


monitoring the trajectories of the colloidal particles using a CCD camera (at the rate of $30 \mathrm{fps}$ ). In a typical experiment, a movie with duration of $10 \mathrm{~s}$ was recorded from a probe particle, and the movie was converted to 300 frames. The trajectory of the particle was then determined through the recorded movie. Afterwards, the formalism explained by Dasgupta et $a l{ }^{[39]}$ was used to calculate viscoelastic properties from colloidal inclusion thermal fluctuations. In this vein, after recoding the time series, the MSD was calculated. Then a local power-law was assigned to the MSD. The power law was determined by the logarithmic time derivative of the MSD. In this method, a second-order polynomial fitting with a Gaussian window was used to calculate the first and second logarithmic time derivatives of the MSD. Finally, the generalized Stokes-Einstein relation was employed to calculate the storage $G^{\prime}(\omega)$ and loss $G^{\prime \prime}(\omega)$ moduli as the functions of angular frequency $\omega$.

\section{RESULTS}

The measured MSDs of the probed particles embedded in the experimental sets of Table 2 are illustrated in Figure 1, as a function of lag time $\tau$. Also, the measured storage modulus and $\tan \delta$ of the experimental sets are shown in Table 2, at the frequency of $10 \mathrm{rad} \mathrm{s}^{-1}$. In addition, the moduli for the sets, as a function of the angular frequency, are presented in Figures 2 and 3.

ANOVA procedures were performed, and a quadratic polynomial model was fitted to the experimental data for the storage modulus at the frequency of $10 \mathrm{rad} \mathrm{s}^{-1}$. The best model equations for both milieus, which consider main influences (SPG178 peptide concentration, $\mathrm{NaCl}$ concentration, and milieu type), two-factor interactions, and curvature influences, are as follows:

$$
\begin{aligned}
& G^{0.24} \\
& =-0.0249+0.636 \mathrm{C}_{\mathrm{SPG}-178}+8.898 \times 10^{-3} \mathrm{C}_{\mathrm{NaCl}}+1.255 \\
& \times 10^{-5} \mathrm{C}_{\mathrm{SPG}-178} \mathrm{C}_{\mathrm{NaCl}}-0.147 \mathrm{C}_{\mathrm{SPG}-178}^{2}-2.440 \\
& \times 10^{-5} \mathrm{C}_{\mathrm{NaCl}}^{2} \quad \text { for DI water } \\
& G^{0.73} \\
& =0.462+0.931 \mathrm{C}_{\mathrm{SPG}-178}+0.0110 \mathrm{C}_{\mathrm{NaCl}}+2.160 \\
& \times 10^{-3} \mathrm{C}_{\mathrm{SPG}-178} \mathrm{C}_{\mathrm{NaCl}}-0.0252 \mathrm{C}_{\mathrm{SPG}-178}^{2}-4.779 \\
& \times 10^{-5} \mathrm{C}_{\mathrm{NaCl}}^{2} \quad \text { for the serum, }
\end{aligned}
$$

where $\mathrm{C}_{\mathrm{SPG}-178}$ and $\mathrm{C}_{\mathrm{NaCl}}$ are SPG-178 peptide and $\mathrm{NaCl}$ concentrations, respectively. $\mathrm{R}$ values of the fitted equations were 0.91 (for DI water) and 0.84 (for the serum). The calculated values of the storage modulus, from the polynomial models, are shown in Table 2, demonstrating that the predicted values from the models are reasonably comparable with the experimental ones.

Another experimental quantity relevant to the mechanical characteristics of hydrogels is $\tan \delta$. It represents the ratio of $G^{\prime \prime}$ and $G^{\prime}$. In this study, $\tan \delta$ was calculated by taking the moduli values at the frequency of $10 \mathrm{rad} \mathrm{s}^{-1}$. ANOVA procedures were performed, and a quadratic polynomial model was fitted to the experimental data for the $\tan \delta$. The best model equations for both milieus are as follows:
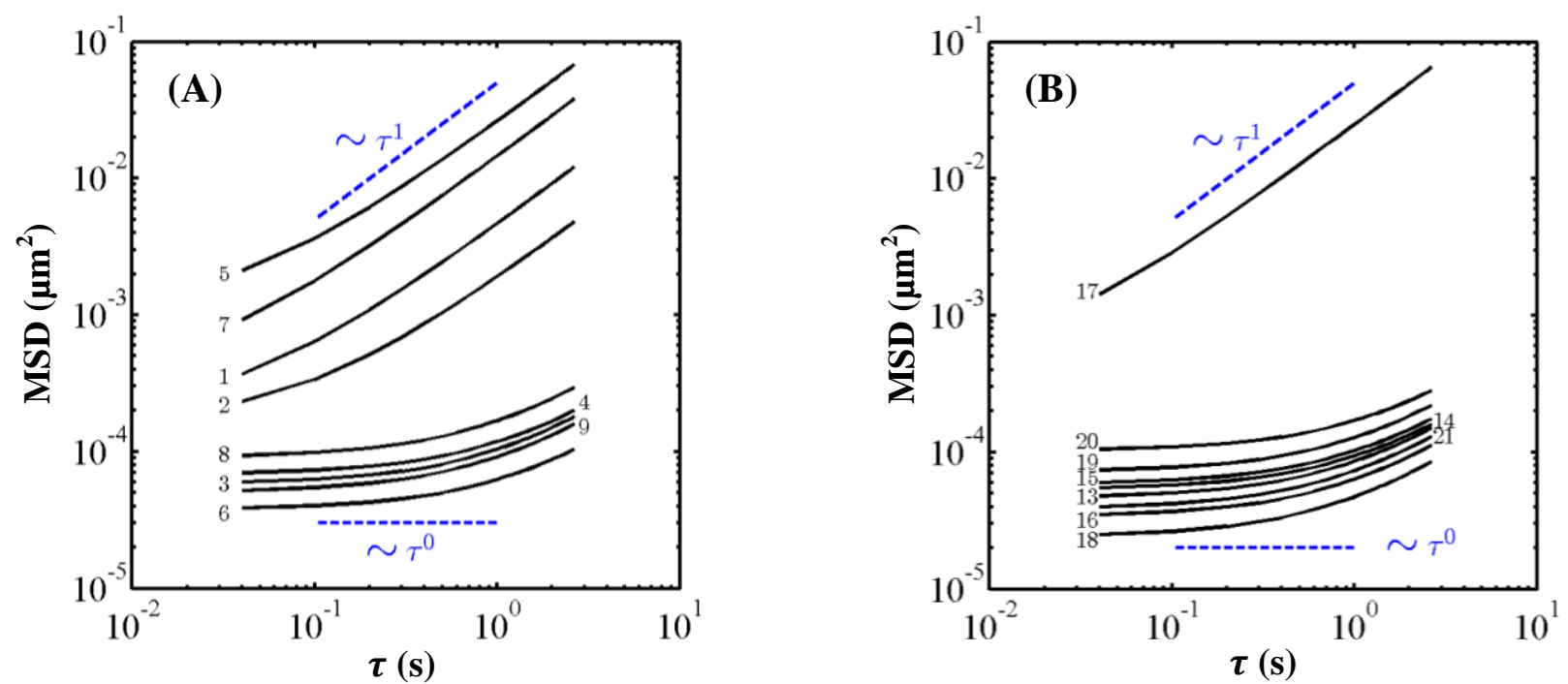

Fig. 1. MSD of probed particles versus lag time $\tau$ in DI water- (A) and the serum-based (B) experiments. The numbers indicate the corresponding sample number shown in Table 2 . The dashed lines are presented merely to guide the eye of diffusive and sub-diffusive motions. 

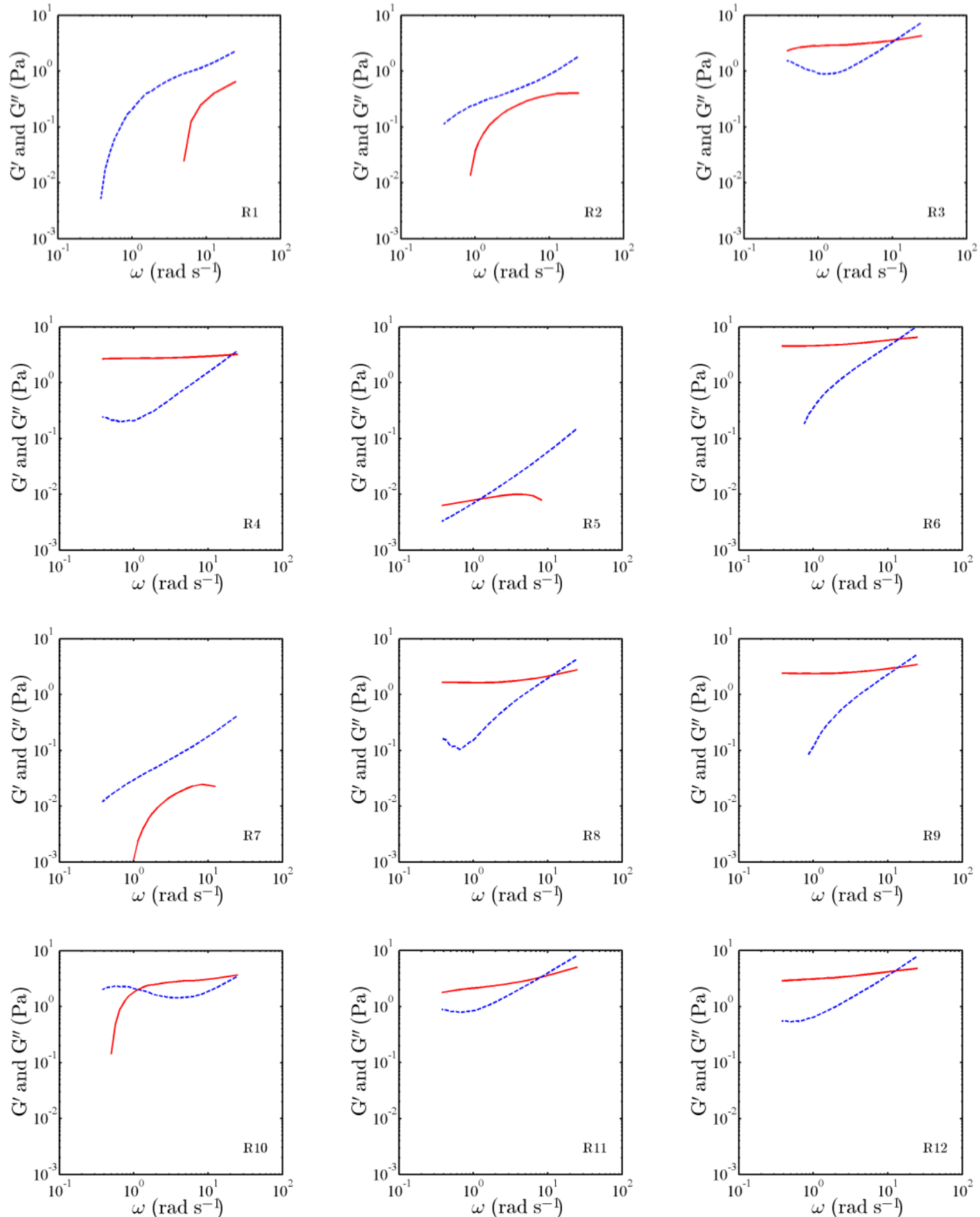

Fig. 2. Storage (solid) and loss (dashed) moduli, as a function of angular frequency $\omega$, for the experimental sets R1-R12 listed in Table 2 .

$$
\begin{aligned}
& \tan \delta)^{-0.72} \\
& =-0.271+0.746 \mathrm{C}_{\mathrm{SPG}-178}+8.147 \times 10^{-3} \mathrm{C}_{\mathrm{NaCl}}+6.495 \\
& \times 10^{-4} \mathrm{C}_{\mathrm{SPG}-178} \mathrm{C}_{\mathrm{NaCl}}-0.196 \mathrm{C}_{\mathrm{SPG}-178}^{2}-2.295 \\
& \times 10^{-5} \mathrm{C}_{\mathrm{NaCl}}^{2} \quad \text { for DI water } \\
& \\
& \quad\left((\tan \delta)^{-1.13}\right. \\
& =+2.122-0.252 \mathrm{C}_{\mathrm{SPG}-178}-0.0136 \mathrm{C}_{\mathrm{NaCl}}+5.356 \\
& \quad \times 10^{-3} \mathrm{C}_{\mathrm{SPG}-178} \mathrm{C}_{\mathrm{NaCl}}-0.0866 \mathrm{C}_{\mathrm{SPG}-178}^{2}+2.111 \\
& \times 10^{-5} \mathrm{C}_{\mathrm{NaCl}}^{2} \quad \text { for the serum, }
\end{aligned}
$$

where $\mathrm{R}$ values of the fitted equations were 0.92 (for DI water) and 0.69 (for the serum). The calculated values of the $\tan \delta$, from the polynomial models, are shown in Table 2, demonstrating that the predicted values from the models are reasonably comparable with the experimental ones.

The surface responses of the storage modulus are presented in Figure 4, with the aid of the statistical models developed for the storage modulus as a 

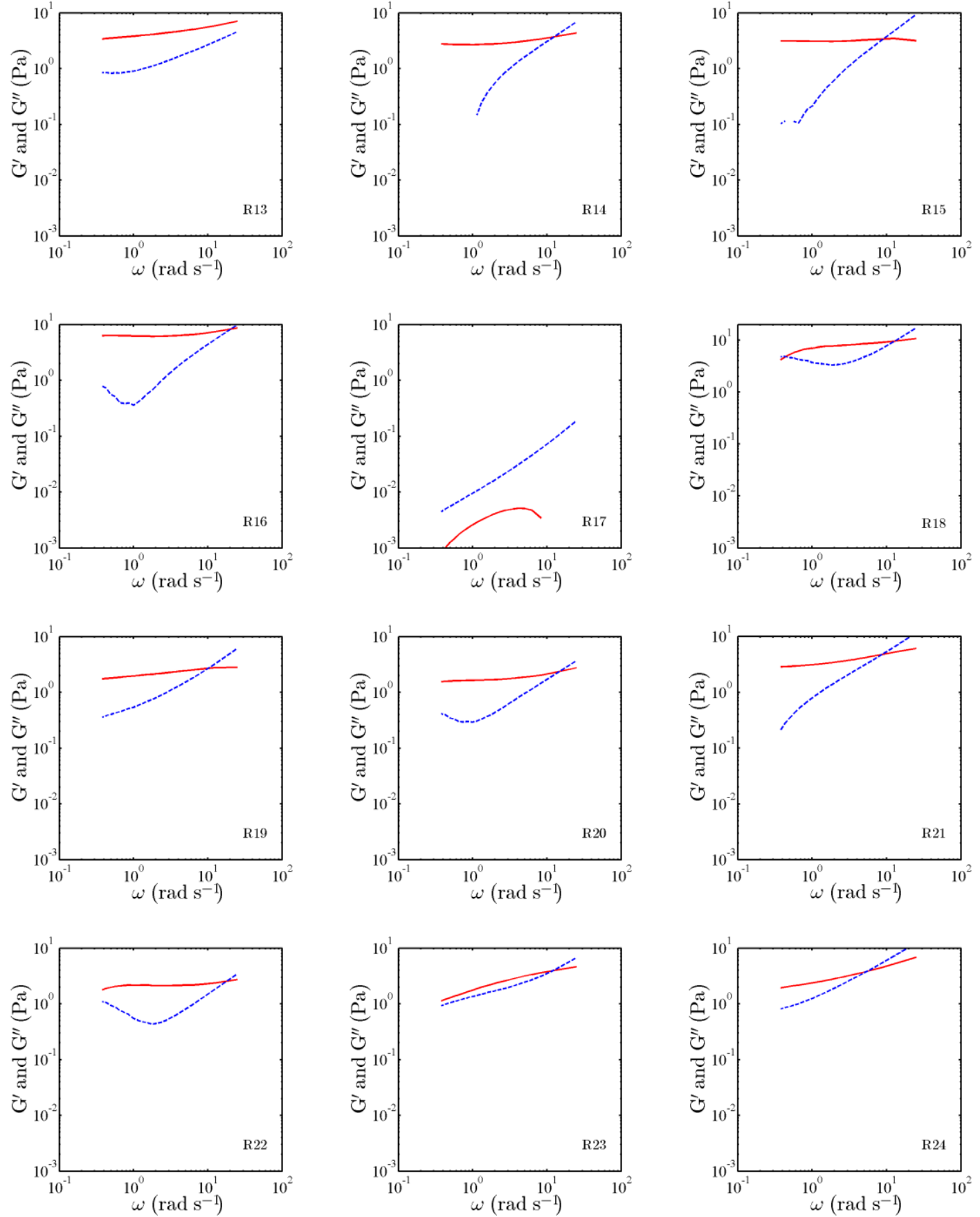

Fig. 3. Storage (solid) and loss (dashed) moduli, as a function of angular frequency $\omega$, for the experimental sets R13-R24 listed in Table 2.

function of the experimentally controllable parameters. Furthermore, the values of the experimentally controllable parameters were optimized to achieve the highest value of $G^{\prime}$ and the lowest value of $\tan \delta$, exploiting the numerical optimization method provided by Design-Expert 7.0 Software. For the optimization, the SPG-178 concentration was set between 0.45 and 3 $\mathrm{g} / \mathrm{L}$. The optimum value for the SPG-178 concentration was obtained in $3 \mathrm{~g} / \mathrm{L}$. The milieu type had to be the blood serum to achieve the optimization objective. Also, the optimum value for $\mathrm{NaCl}$ concentration was different in the DI water and blood serum. 

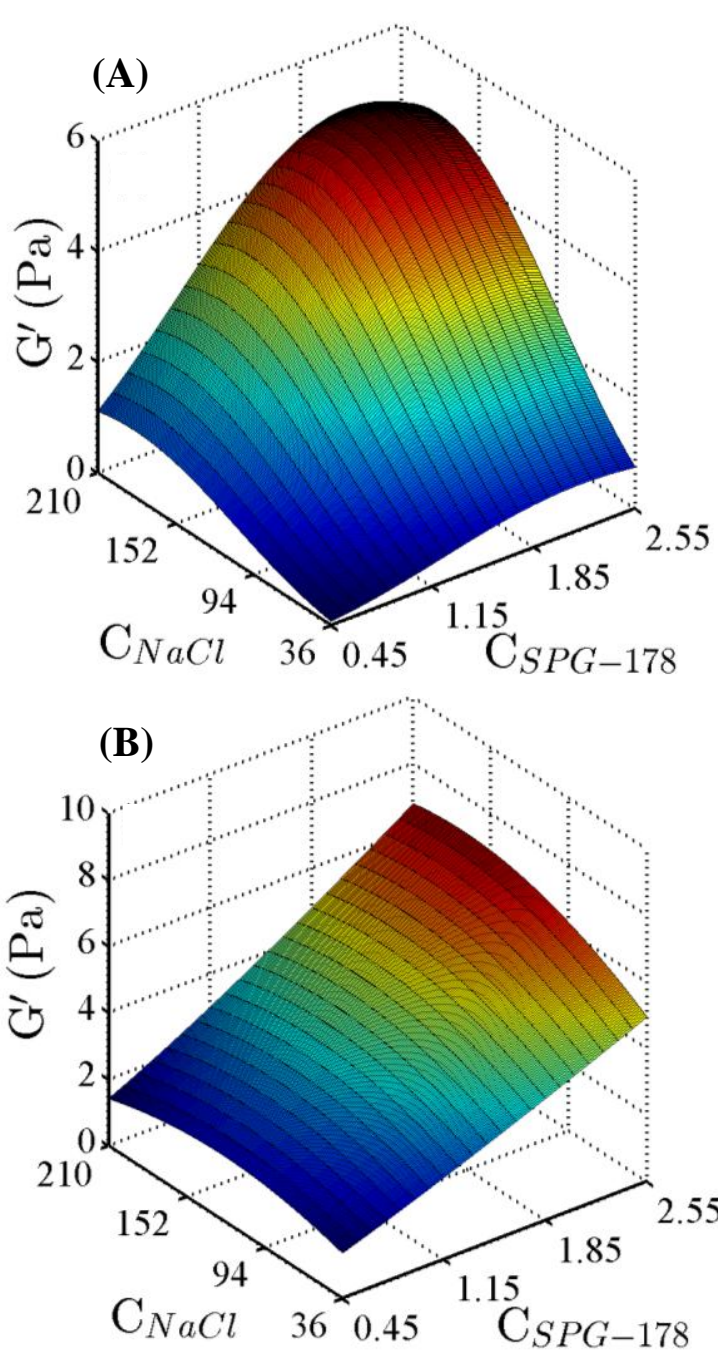

Fig. 4. Effects of the SPG-178 peptide and $\mathrm{NaCl}$ concentrations on the storage modulus of the SPG-178 hydrogels, predicted by equations 1 and 2 , in the milieus of DI water (A) and serum (B).

\section{DISCUSSION}

In the MSDs, two distinct regimes are observed as depicted in Figure 1. In the first regime, the MSDs scale as $\sim \tau^{1}$, indicating diffusive motion in a viscous fluid. In the second one, the MSDs scale as $\sim \tau^{0}$, indicating sub-diffusive motion in a viscoelastic medium $^{[31]}$. The diffusive motion occurs within samples $1,2,5,7$, and 17 , where the sol-gel transition is not observed; however, the sub-diffusive motion occurs within the other samples, indicating the sol-gel transition for the corresponding samples.

The characteristics of the measured storage and loss moduli, reported in Figures 2 and 3, are in agreement with the characteristics of probed motions observed in Figure 1. For samples 1, 2, 5, 7, and 17, the storage modulus does not have a distinct low-frequency plateau. In the samples, at low frequencies, the storage modulus is less than the corresponding loss modulus. On the other hand, for other samples, the storage modulus has a distinct low-frequency elastic plateau, and a cross-over frequency is evident. For such samples, the storage moduli are relatively high compared to those for samples 1, 2, 5, 7, and 17 .

According to Figure 4, both the SPG-178 peptide and $\mathrm{NaCl}$ concentrations modulate the surface responses. Interestingly, in the surface shown in Figure 4B, there is plateau in relation to $\mathrm{NaCl}$ concentration, indicating that variation of the $\mathrm{NaCl}$ concentration does not considerably affect the surface response in the serum. However, $\mathrm{NaCl}$ concentration considerably modulates the surface response in DI water, and increasing $\mathrm{NaCl}$ concentration results in the increment of the response. With the elevation of $\mathrm{NaCl}$ concentration, the peptides self-assemble once the electrostatic repulsions among the peptides become less than hydrophobic attractions. For each peptide, there is a certain added-salt concentration, so-called CCC, where at concentrations beyond the CCC, the corresponding peptide becomes a gel $^{[40]}$. At such concentrations, repulsive forces among peptides vanish, the peptides aggregate, and the corresponding environment becomes a gel.

To understand how the added salt modulates the interactions among the SPG-178 peptides, we considered the structure of the SPG-178 peptide. The peptide has 7 hydrophobic (6 leucine and 1 alanine) and 6 hydrophilic (4 arginine and 2 aspartic acid) residues. Leucine has a large hydrophobic side chain $^{[41]}$. Thus, with a slight $\mathrm{NaCl}$ induction, hydrophobic forces become dominant over repulsive forces and the peptides rapidly converge to cylindrical $\beta$-sheet structures, in which the hydrophobic sides are inserted into the interior of the fiber ${ }^{[11]}$.

It must be recalled that the effect of $\mathrm{NaCl}$ concentration on the storage modulus in DI water is more than that of the serum. There are various cations and anions in the serum that affect the self-assembly, even in the absence of $\mathrm{NaCl}$. Thus, in the absence of $\mathrm{NaCl}$, while the electrostatic repulsions are considerable in DI water, the interactions are screened in the serum. Accordingly, the addition of $\mathrm{NaCl}$ is of importance in DI water but not in the serum. Further research on the effect of the serum content on the viscoelastic properties of the corresponding hydrogels is recommended.

To sum up, we combined microrheology and RSM for comparative and comprehensive analysis of expensive polymeric drugs and gels. By integrating microrheology and RSM, the viscoelastic properties of SPG-178 peptide hydrogels were examined 
considering the impact of the SPG-178 peptide and $\mathrm{NaCl}$ concentrations, and milieu type. Statistical models were obtained, accounting for the impact of the experimentally controllable parameters on the viscoelastic properties. The statistical models were employed for finding the optimum value of the parameters to maximize the storage modulus and minimize $\tan \delta$. The optimum self-assembling condition for SPG-178 SApeptides was in the blood serum with the peptide concentration of $3 \mathrm{~g} / \mathrm{L}$. In conclusion, upon the type of materials and available facilities, other microrheological techniques, such as multiple particle tracking microrheology, optical tweezers, and microfluidics could be integrated with statistical methods to optimize soft matter formulations for a variety of applications.

CONFLICT OF INTEREST. None declared.

\section{REFERENCES}

1. Gelain F, Horii A, Zhang S. Designer self-assembling peptide scaffolds for 3-d tissue cell cultures and regenerative medicine. Macromolecular bioscience 2007; 7(5): 544-551.

2. Seow WY, Hauser CAE. Short to ultrashort peptide hydrogels for biomedical uses. Material today 2014; 17(8): $381-388$

3. Ichihara Y, Kaneko M, Yamahara K, Koulouroudias M, Sato N, Uppal R, Yamazaki K, Saito S, Suzuki K. Selfassembling peptide hydrogel enables instant epicardial coating of the heart with mesenchymal stromal cells for the treatment of heart failure. Biomaterials 2018; 154: 12-23.

4. Yang Y, Khoe U, Wang X, Horii A, Yokoi H, Zhang S. Designer self-assembling peptide nanomaterials. Nanotoday 2009; 4(2): 193-210.

5. Maude S, Miles DE, Felton SH, Ingram J, Carrick LM, Wilcox RK, Ingham E, Aggeli A. De novo designed positively charged tape-forming peptides: self-assembly and gelation in physiological solutions and their evaluation as 3D matrices for cell growth. Soft matter 2011; 7: 8085-8099.

6. Loo Y, Zhang S, Hauser CAE. From short peptides to nanofibers to macromolecular assemblies in biomedicine. Biotechnology advances 2012; 30(3): 593603.

7. Zhang S, Holmest T, Lockshin C, Rich A. Spontaneous assembly of a self-complementary oligopeptide to form a stable macroscopic membrane. Proceedings of the national academy of sciences of the United States of America 1993; 90(8): 3334-3338.

8. Ellis-Behnke RG, Liang YX, Tay DK, Kau PW, Schneider GE, Zhang S, Wu W, So KF. Nano hemostat solution: immediate hemostasis at the nanoscale. Nanomedicine 2006; 2(4): 207-215.
9. Zhang N, Luo Y, He L, Zhou L, Wu W. A self-assembly peptide nanofibrous scaffold reduces inflammatory response and promotes functional recovery in a mouse model of intracerebral hemorrhage. Nanomedicine 2016; 12(5): 1205-1217.

10. Zhao WK, He B, Zhou A, Li Y, Chen X, Yang Q, Chen B, Qiao B, Jiang D. D-RADA16-RGD-reinforced nanohydroxyapatite/polyamide 66 ternary biomaterial for bone formation. Tissue engineering and regenerative medicine 2019; 16(2): 177-189.

11. Yamamoto K, Yokoi H, Otani A. Hierarchical structure of the fibrillar hydrogel network of a self-assembled synthetic peptide revealed by X-ray scattering and atmospheric scanning electron microscopy. Macromolecular symposia 2015; 358(1): 85-94.

12. Uesugi K, Sakaguchi H, Hayashida Y, Hayashi R, Baba K, Suganuma Y, Yokoi H, Tsujikawa M, Nishida K. A self-assembling peptide gel as a vitreous substitute: a rabbit study. Investigative ophthalmology and visual science 2017; 58(10): 4068-4075.

13. Tsukamoto J, Naruse K, Nagai Y, Kan S, Nakamura N, Hata M, Omi M, Hayashi T, Kawai T, Matsubara T. Efficacy of a self-assembling peptide hydrogel, SPG178-gel, for bone regeneration and three-dimensional osteogenic induction of dental pulp stem cells. Tissue engineering part A 2017; 23(23-24): 1394-1402.

14. Ando K, Imagama $S$, Kobayashi K, Ito K, Tsushima M, Morozumi M, Tanaka S, Machino M, Ota K, Nishida K, Nishida Y, Ishiguro N. Effects of a self-assembling peptide as a scaffold on bone formation in a defect. PLoS one 2018; 13(1): e0190833.

15. Ando K, Imagama $S$, Ito $Z$, Kobayashi $K$, Hida $T$, Nakashima $\mathrm{H}$, Ito $\mathrm{K}$, Tsushima $\mathrm{M}$, Ishikawa $\mathrm{Y}$, Matsumoto A, Nishida K, Nishida Y, Ishiguro N. Selfassembling peptide reduces glial scarring, attenuates posttraumatic inflammation, and promotes neurite outgrowth of spinal motor neurons. Spine (Phila Pa 1976) 2016; 41(20): E1201-E1207.

16. Komatsu S, Nagai Y, Naruse K, Kimata Y. The neutral self-assembling peptide hydrogel SPG-178 as a topical hemostatic agent. PLoS one 2014; 9(7): e102778.

17. Nagai Y, Yokoi H, Kaihara K, Naruse K. The mechanical stimulation of cells in 3D culture within a self-assembling peptide hydrogel. Biomaterials 2012; 33(4): 1044-1051.

18. Rostami S., Garipcan B. Rheological Properties of Biological Structures, Scaffolds and Their Biomedical Applications. In: Artmann G., Artmann A., Zhubanova A., Digel I. (eds) Biological, Physical and Technical Basics of Cell Engineering. Springer, Singapore; 2018 pp. 119-140.

19. De Leon Rodriguez LM, Hemar Y, Cornishc J, Brimble MA. Structure-mechanical property correlations of hydrogel forming $\beta$-sheet peptides. Chemical society reviews 2016; 45(17): 4797-4824.

20. Pugliese R, Fontana F, Marchini A, Gelain F. Branched peptides integrate into self-assembled nanostructures and enhance biomechanics of peptidic hydrogels. Acta biomaterialia 2017; 66: 258-271.

21. Wang TW, Chang KC, Chen LH, Liao SY, Yeha CW, 
Chuang YJ. Effects of an injectable functionalized selfassembling nanopeptide hydrogel on angiogenesis and neurogenesis for regeneration of the central nervous system. Nanoscale 2017; 9(42): 16281-16292.

22. Campione M, Gelain F, Hwang W, Sassella A, Taraballi F, Vescovi AL. Effect of functionalization on the selfassembling propensity of $\beta$-sheet forming peptides. Soft matter 2009; 5: 660.

23. Ozbas B, Kretsinger J, Rajagopal K, Schneider JP, Pochan DJ. Salt-triggered peptide folding and consequent self-assembly into hydrogels with tunable modulus. Macromolecules 2004; 37: 7331-7337.

24. Feng Y, Taraban M, Yu YB. The effect of ionic strength on the mechanical, structural and transport properties of peptide hydrogels. Soft matter 2012; 8(46): 1172311731.

25. Otsuka T, Maeda T, Hotta A. Effects of salt concentrations of the aqueous peptide-amphiphile solutions on the sol-gel transitions, the gelation speed, and the gel characteristics. The journal of physical chemistry B 2014; 118(39): 11537-11545.

26. Greenfield MA, Hoffman JR, de la Cruz MO, Stupp SI. Tunable mechanics of peptide nanofiber gels. Langmuir 2010; 26(5): 3641-3647.

27. Owczarz M, Bolisetty S, Mezzenga R, Arosio P. Sol-gel transition of charged fibrils composed of a model amphiphilic peptide. Journal of colloid and interface science 2015; 437: 244-251.

28. Cicuta P, Donald AM. Microrheology: a review of the method and applications. Soft matter 2007; 3: 14491455.

29. Oppong FK, de Bruyn JR. Mircorheology and jamming in a yield-stress fluid. Rheologica acta 2011; 50(4): 317-326.

30. Moschakis T. Microrheology and particle tracking in food gels and emulsions. Current opinion in colloid and interface science 2013; 18(4): 311-323.

31. Veerman C, Rajagopal K, Palla CS, Pochan DJ, Schneider JP, Furst EM. Gelation kinetics of $\beta$-hairpin peptide hydrogel networks. Macromolecules 2006; 39(19): 6608-6614.

32. Breedveld V, Pine DJ. Microrheology as a tool for high- throughput screening. Journal of materials science 2003; 38(22): 4461-4470.

33. Corrigan AM, Donald AM. Passive microrheology of solvent-induced fibrillar protein networks. Langmuir 2009; 25(15): 8599-8605.

34. Chen DT, Weeks ER, Crocker JC, Islam MF, Verma R, Gruber J, Levine AJ, Lubensky TC, Yodh AG. Rheological microscopy: local mechanical properties from microrheology. Physical review letters 2003; 90(10): 108301.

35. Seyedkarimi MS, Mirzadeh H, Bagheri-Khoulenjan S. On the analysis of microrheological responses of selfassembling RADA16 peptide hydrogel. Journal of biomedical materials research part A 2019; 107(2): 330-338.

36. Li Q, Cheung WH, Chow KL, Ellis-Behnke RG, Chau Y; Factorial analysis of adaptable properties of selfassembling peptide matrix on cellular proliferation and neuronal differentiation of pluripotent embryonic carcinoma. Nanomedicine 2012; 8(5): 748-756.

37. Lam J, Carmichael ST, Lowry WE, Segura T. Hydrogel design of experiments methodology to optimize hydrogel for iPSC-NPC culture. Advanced healthcare materials 2015; 4(4): 534-539.

38. Bagheri-Khoulenjani S, Mirzadeh H, Etrati-Khosroshahi M, Shokrgozar MA. Development of a method for measuring and modeling the $\mathrm{NH}_{2}$ content and crosslinking density of chitosan/gelatin/ nanohydroxyapatite based microspheres. Polymer testing 2016; 51: 20-28.

39. Dasgupta BR, Tee SY, Crocker JC, Frisken BJ, and Weitz DA. Microrheology of polyethylene oxide using diffusing wave spectroscopy and single scattering. Physical review E 2002; 65(5 Pt 1):051505.

40. Caplan MR, Moore PN, Zhang S, Kamm RD, Lauffenburger DA. Self-assembly of a $\beta$-sheet protein governed by relief of electrostatic repulsion relative to van der waals attraction. Biomacromolecules 2000; 1(4): 627-631.

41. Narayanan C, Dias CL. Hydrophobic interactions and hydrogen bonds in $\beta$-sheet formation. The journal of chemical physics 2013; 139(11): 115103. 